\title{
TO STUDY EFFICACY OF AMISULPRIDE IN TREATMENT OF SCHIZOPHRENIA.
}

Dr. Om Prakash Raichandani ${ }^{1}$ (Associate Professor), Dr Abhijeet Kadam ${ }^{2}$ (Scientist C) \& Mrs. Sapna Raichandani $^{3}$ (Honorary Lecturer)

Department of Psychiatry, N.S.C.B. Medical College, Jabalpur ${ }^{1}$

ICMR-National Aids Research Institute, Pune ${ }^{2}$

Shri Ram College of Pharmacy, Jabalpur ${ }^{3}$

Article Info: Received 30 November 2019; Accepted 29 December 2019

DOI: https://doi.org/10.32553/ijmbs.v3i12.834

Corresponding author: Dr. Om Prakash Raichandani

Conflict of interest: No conflict of interest.

\section{Abstract}

The study was performed at the Department of Pharmacology in collaboration with Department of Psychiatry, NSCB Medical College, Jabalpur. The maximum numbers of patients in were in reproductive age group that is in between 20 to 49 years. The mean age in Amisulpride group was $33.26( \pm 10.23)$ years while in Olanzapine group it was $31.25( \pm 12.22)$ years.

Schizophrenia was more common (80\%) in younger (20-49years) age group. In our study the male /female ratio was 1.7. Our study supports the notion that Schizophrenia is more common in Married and Urban population. Only one patient from Olanzapine Group suffered Extrapyramidal symptoms of moderate severity requiring withdrawal from study.2 patients from Olanzapine group and 1 patient from Amisulpride group had Tremors and Akathesia of mild severity. There was no emergence of Extrapyramidal symptoms in rest of the patients ( $p>.05)$

Keywords: Efficacy, Amisulpride, Olanzapine \& Schizophrenia.

\section{Introduction}

Schizophrenia is the term for a group of disorders marked by chronicity, impaired behavioral function, and disturbances of thinking and affect. ${ }^{1}$

Eugene Bleuler (1857 to 1939) was a Swiss psychiatrist generally credited for coining the term schizophrenia, of which he described primary symptoms of abnormal associations, abnormal affect, autistic behavior, and ambivalence the four A's.

Schizophrenia is a severe mental disorder which accounts for much suffering of those affected and their families, in addition to a cost to society estimated as $1.1 \%$ of the total burden of disease (in terms of DALYs - disability adjusted life-years) and $2.8 \%$ of the total YLDs (years lived with disability) (Mental health policy and service development) ${ }^{2 \& 3}$

In India, for a population of nearly one billion people, there are an estimated four million people with schizophrenia, with different degrees of impact on some 25 million family members. (Mental health policy and service development $)^{4 \& 5}$
Life expectancy is also decreased as compared to the general population, not only due to suicide but in particular due to cardiovascular disease.

\section{Material \& Method}

The study was performed at the Department of Pharmacology in collaboration with Department of Psychiatry, NSCB Medical College, Jabalpur. Here patients were offered outpatients consultation and hospital admission when necessary.

\section{Selection of Cases}

The participants were of at least 18 years of age and below 60 years who had provided written informed consent before any study procedure was initiated.

\section{Inclusion Criteria}

- $\quad$ DSM -IV criteria for schizophrenia.

- Patient should not require hospitalization

- $\quad$ There should not be any past history or physical disorder that would likely to deteriorate during participation 
- There should be no abnormal lipid profile, ECG, abnormal blood glucose levels or abnormal BMI that would suggest deterioration during treatment.

- Should be able to communicate in Hindi/English.

\section{Exclusion Criteria}

- Patients requiring ECT or hospitalization.

- Patients with hypertension, Cardiac Disorder

- Pregnant/Nursing females.

- Patients with suicidal tendency.

- Unable to provide informed consent.

This study was carried out from March 2007 to September2009.This study was Double Blind. Drugs were provided to me in SEALED WHITE OPAQUE PAPER ENVELOPES labeled either as " $A$ " or " 1 ". The patients were RANDOMIZED either to receive drug $A$ or drug 1 as per.

\section{Results}

\section{TABLE 1: DEMOGRAPHIC DATA}

\begin{tabular}{lllll}
\hline AGE & AMISULPIRIDE & OLANZAPINE & TOTAL & Percentage \\
\hline $\mathbf{2 0}$ & 2 & 1 & 3 & $5 \%$ \\
\hline $\mathbf{2 0 - 2 9}$ & 8 & 7 & 15 & $25 \%$ \\
\hline $\mathbf{3 0 - 3 9}$ & 8 & 11 & 19 & $31.7 \%$ \\
\hline $\mathbf{4 0 - 4 9}$ & 8 & 6 & 14 & $23.3 \%$ \\
\hline $\mathbf{5 0 - 5 9}$ & 3 & 4 & 7 & $11.7 \%$ \\
\hline $\mathbf{6 0 - 6 9}$ & 1 & 1 & 2 & $3.3 \%$ \\
\hline TOTAL & 30 & 30 & 60 & $100 \%$ \\
\hline
\end{tabular}

The maximum number of patients in was in reproductive age group that is in between 20 to 49 years. The mean age in Amisulpride group was $33.26( \pm 10.23)$ years while in Olanzapine group it was $31.25( \pm 12.22)$ years.

TABLE 2: LOCALITY WISE DISTRIBUTION

\begin{tabular}{llll}
\hline & AMISULPIRIDE & OLANZAPINE & Total \\
\hline URBAN & 18 & 20 & $38(63.3 \%)$ \\
\hline RURAL & 12 & 10 & $22(36.7 \%)$ \\
\hline & 30 & 30 & 60 \\
\hline
\end{tabular}

TABLE 3: DISTRIBUTION ACCORDING TO DURATION OF ILLNESS

\begin{tabular}{llll}
\hline DURATION & AMISULPIRIDE & OLANZAPINE & TOTAL \\
\hline$<1$ YEAR & 6 & 4 & 10 \\
\hline $1-4$ YEAR & 20 & 21 & 41 \\
\hline 5-9 YEAR & 4 & 5 & 9 \\
\hline TOTAL & 30 & 30 & 60 \\
\hline
\end{tabular}

$16.6 \%$ of patients presented with duration of disease less than 1 year. Rest all patients had a chronic History with mean duration of illness of 1.4 ( \pm 1.32$)$ years.
TABLE 4: DROP OUT RATE

\begin{tabular}{lll}
\hline & AMISULPIRIDE & OLANZAPINE \\
\hline $\begin{array}{l}\text { No. of Patients Lost to Follow } \\
\text { up }\end{array}$ & 7 & 5 \\
\hline $\begin{array}{l}\text { No. of Patients Lost due to } \\
\text { Adverse Effects: }\end{array}$ & 2 & 1 \\
\hline
\end{tabular}

Total 12 patients $(n=60)$ were lost to follow up, 05 from the Olanzapine group and 07 patients from the Amisulpiride group. The reason could not be determined since these patients never turned up to the Psychiatry OPD.

One patient from the Olanzapine group suffered from severe Tremors and Akathesia during the 2ND week of trial period so was withdrawn from study and started on anticholinergic medication.

02 female patients in the Amisulpiride group complained of delayed menses on 30TH day follow up. They were referred to Gynaecologist and discontinued from the trial.

Hence Overall dropout rate in our study was $25 \%$.

\section{USE OF SEDATIVE:}

13 patients in Amisulpride group and 10 patients in Olanzapine group were prescribed Tab. Alprazolam $0.25 \mathrm{mg}$ on 15th day of study. 6 patients in Olanzapine group required to continue the medication throughout study while rest discontinued Tab. Alprazolam on subsequent visit.

Only 03 patients in the Amisulpride group discontinued the sedative while rest all continued the drug.

\section{Discussion}

In this Double blind Randomized Study final analysis was done in 21 patients from the Amisulpride group and 24 in Olanzapine group. ${ }^{6}$

All the patients were initially given Olanzapine $5 \mathrm{mg}$ and Amisulpride $100 \mathrm{mg}$ in opaque sealed envelopes. 3 patients $(12.5 \%)$ from Olanzapine group and 2 patients in Amisulpride group (9.5\%) showed improvement at the initial dose. ${ }^{7}$ they showed more than $10 \%$ reduction in BPRS and CGI scores on the first follow up. For rest of the patients the dose was doubled by providing 2 envelopes since 15th day. That is 21 patients in Olanzapine group and 19 patients in Amisulpride group received double dose (10mg Olanzapine and 200mg Amisulpride) for rest of the study duration. ${ }^{8 \& 9}$ 
Both the drugs were equally efficacious when these drugs were compared on Physician administered CGI scale with a mean change in Severity scores of 2.095( \pm .831 ) in Amisulpride Group and 2.125( \pm 0.68 ) in Olanzapine group. The improvement in scores were comparable in both the groups. ${ }^{10}$

\section{Conclusion}

Schizophrenia was more common (80\%) in younger (20-49years) age group. In our study the male /female ratio was 1.7. Our study supports the notion that Schizophrenia is more common in Married and Urban population.

Only one patient from Olanzapine Group suffered Extrapyramidal symptoms of moderate severity requiring withdrawal from study. 2 patients from Olanzapine group and 1 patient from Amisulpride group had Tremors and Akathesia of mild severity. There was no emergence of Extrapyramidal symptoms in rest of the patients ( $p>.05)$

\section{References}

1. Akhondzadeh, Shahin. 2006 Pharmacotherapy of Schizophrenia: The Past, Present and Future Current Drug Therapy, 1(1), pp. 1-7.

2. Babulas, V, Factor-Litvak, P, Goetz, R, Schaefer, CA, Brown, AS. 2006. Prenatal exposure to maternal genital and reproductive infections and adult schizophrenia. American Journal of Psychiatry, 163(5), pp.927-9.
3. Danion, JM, Rein, W, Fleurot, $O$, and the Amisulpride Study Group, 1999 improvement of Schizophrenic Patients With Primary Negative Symptoms Treated With Amisulpride American Journal of Psychiatry, 156,pp.610-616.

1. Lecrubier, Y, Boyer, P, Turjanski, S, Rein, W., 1997. Amisulpride versus imipramine and placebo in dysthymia and major depression. Amisulpride Study Group.Journal of Affect Disorder, 43(2),pp. 95-103.

4. Leucht, S, Pitschel-Walz, G, Engel, R, and Kissling, W., 2002. Amisulpride, an unusual atypical antipsychotic: a Meta-analysis of randomized controlled trials. American Journal of Psychiatry 159, pp. 180-190.

5. Loo, H, Poirier-Littre, MF, Theron, MF, Rein, W, and Fleurot, O., 1997.Amisulpride versus placebo in the medium-term treatment of the negative symptoms of schizophrenia The British Journal of Psychiatry 170, pp.18-22.

6. Marder, SR, Meibach, RC. 1994. Risperidone in the treatment of schizophrenia. American Journal of Psychiatry, 151 pp. 825-835.

7. Möller, HJ, Boyer, P. Fleurot, O. Rein, W. and PRODASLP Study Group., 1997 Improvement of acute exacerbations of schizophrenia with amisulpride: a comparison with haloperidol, Psychopharmacology, 132(4), pp.396-401.

8. Paillere-Martinot, ML, Martinot, JL, and Aubin, F., 1995. Improvement of some schizophrenic deficit symptoms with low doses of Amisulpride American Journal of Psychiatry, 152, pp.130-134.

9. Timothy, JR. Lambert and David JC. 2003. Pharmacological approaches to the management of schizophrenia MJA, 178 (9), pp. S57-S61. 